\title{
Entre Brasil, Portugal e Cabo Verde: reflexões sobre os itinerários de uma pesquisa em Educação Artística
}

\author{
Denise Perdigão Pereira \\ Universidade do Porto
}

\begin{abstract}
"Não sabendo que era impossível, foi lá e fez".
Jean Cocteau
\end{abstract}

\section{Resumo}

O ensaio busca explicitar os itinerários de uma pesquisa de doutorado no âmbito da Educação Artística, realizado em regime de Cotutela entre a Universidade do Porto e a Universidade Federal de Minas Gerais. O campo da investigação localiza-se na ilha de São Vicente, Cabo Verde. O foco do ensaio recairá na discussão e apresentação de reflexões acerca da metodologia delineada para a realização da investigação. Defende-se a ideia de que para a condução de uma pesquisa em Educação Artística é preciso alguma antecipação no delineamento de seu design. Entretanto, procura-se destacar também o imprevisto, as adversidades, bem como as surpresas que podem surgir nesse processo como ingredientes fecundos para a construção ou reconstrução de conhecimentos, na medida em que tais elementos propiciam a desestabilização de noções e, portanto o surgimento de novos saberes.

Palavras-Chave: Itinerários de Pesquisa, Educação Artística, Brasil, Portugal, Cabo Verde.

\section{Abstract}

The essay aims to explain the itineraries of a doctoral research in the field of Art Education, conducted in partnership between Universidade do Porto and Universidade Federal de Minas Gerais. The field of research is located in Saint Vincent Island, Cape Verde. The focus of the essay will be on the discussion and presentation of the reflections regarding the methodology utilized in the realization of the study. It is defended in Art Education that it is necessary an anticipation of the definition of the research design. However, it is also important to highlight that the unpredictable, the adversities, as well as the surprises that may occur in the process are fruitiful for the construction or reconstruction of knowledge to the 
extend that these elements provide the desestabilization of notions, and therefore the rise of new knowledge.

Keywords: Research itineraries, Art education, Brazil, Portugal, Cape Verde.

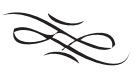

\section{Introdução}

O presente ensaio consiste em parte da minha pesquisa de doutoramento, realizado em regime de Cotutela ${ }^{1}$ entre a Faculdade de Belas Artes da Universidade do Porto, instituição onde iniciei o curso no ano de 2013, e a Faculdade de Educação da Universidade Federal de Minas Gerais.

A investigação tem como objetivo discutir o campo de possibilidades da Educação Artística como lugar de experimentação utópica, uma vez que destaca a necessidade de que sejam desenvolvidas formas de vida social substitutivas aos valores predominantes ao ethos do capitalismo tardio (MOUFFE, 2007). Para tanto, foi tomada como unidade de análise a Mindelo_Escola Internacional de Arte, M_EIA ${ }^{2}$, criada no ano de 2005, na ilha de São Vicente, no país de Cabo Verde.

A escolha pelo estudo dessa instituição deve-se a dois motivos: o primeiro deles refere-se ao fato de a escola constituir-se em única instituição de formação artística superior no país. O segundo motivo relaciona-se ao caráter singular dessa escola de arte, expresso desde a sua gênese. Surgida como desdobramento dos projetos desenhados pela organização não governamental cabo-verdiana Atelier Mar³ ${ }^{3}$ criada em 1979, a es-

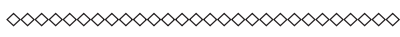

1 Segundo o Departamento de Relações Internacionais da Universidade Federal de Minas Gerais, "a cotutela de Tese é uma modalidade que permite ao estudante de Doutorado realizar sua Tese sob a responsabilidade de dois orientadores: um no Brasil e outro em um país estrangeiro. Ambos exercem sua competência conjuntamente em relação ao estudante, que deve permanecer nas duas instituições por períodos equivalentes. A Tese é defendida uma única vez, no Brasil ou no outro país, e são atribuídos ao estudante diplomas de Doutorado dos dois países. É exigida a assinatura de uma convenção entre as instituições envolvidas, específica para cada doutorando". Disponível em: https://www.ufmg.br/dri/pos-graduacao/cotutela/. Data de acesso: 23/06/2016.

2 De acordo com o site a instituição, "M_EIA, MINDELO_Escola Internacional de ARTE reconhecida juridicamente como Instituto Universitário de Arte, Tecnologia e Cultura constitui-se como o primeiro, e até agora o único, espaço de ensino superior nas áreas das artes e do design incluindo a formação de professores do ensino secundário nas respectivas áreas em Cabo Verde". A Escola passou a oferecer também, desde o ano de 2015, o curso de Arquitetura. "M_EIA visa despertar dinâmicas criativas baseadas no conhecimento profundo das matrizes sociais do país, segundo abordagens interdisciplinares e inter-culturais”. Disponível em: http://meia.edu.cv/. Data de acesso: 23/06/2016.

3 "Criado em 1979, o Atelier Mar tem desenvolvido programas de formação e pesquisa para a promoção e desenvolvimento das artes e ofícios em Cabo Verde. Mantêm a sede em Mindelo na ilha de S. Vicente". 
cola possui estreita ligação com os trabalhos de desenvolvimento sócio-comunitários realizados pela ONG, numa relação de estreita parceria entre as duas instituições.

Jacques Rancière (2009), Chantal Mouffe (2014) e Dennis Atkinson (2008) constituem-se nos referencias teóricos centrais da pesquisa. Os dois primeiros autores discutem as práticas artísticas como possibilidade de questionamento da hegemonia dominante no contexto atual. Mouffe utiliza o termo "artivismo" para designar "um movimento contra-hegemônico e contra a apropriação capitalista da estética, a fim de garantir o seu processo de valorização". O M_EIA situa-se, justamente na convergência destes dois pontos, pois assume papel de relevo no questionamento dos instrumentos de dominação a respeito das concepções hegemônicas de arte e de educação ocidental.

A pesquisa procura responder às seguintes questões: Qual(is) é(são) a(s) concepção(ões) de Educação Artística e de arte(s) norteadora(s) do trabalho desenvolvido no M_EIA? Qual(is) é(são) a(s) concepção(ões) de investigação aplicada? Qual(is) a(s) concepção(ões) de desenvolvimento local está(ao) presentes nos projetos realizados pela escola junto às populações? Esta(s) concepção(ões) são conciliável(is) com a lógica do desenvolvimento participativo? Neste sentido, em qual medida a arte pode favorecer (ou não) a relação educativa que se estabelece entre alunos de uma escola de arte e comunidades locais?

A ferramenta metodológica adotada implica em uma análise em profundidade do contexto em questão, própria dos estudos de caso. Nesse sentido, foram realizadas entrevistas com os diversos atores inseridos no contexto do M_EIA e nas comunidades: reitor, diretor, professores, alunos e comunidades. Além disso, foram recolhidas fontes documentais, tais como o projeto político-pedagógico da escola, programas de ensino, fotografias etc.

O presente ensaio procura tecer algumas reflexões a respeito dos itinerários de uma investigadora brasileira cuja temática de estudo situa-se em Cabo Verde, conforme salientando, mas que durante a condução da tese, teve que se mover entre o seu país de origem, Brasil, Cabo Verde, obviamente, e Portugal. Assim, o foco de discussão do ensaio recairá, sobretudo, na metodologia delineada para a realização da investigação, já

\footnotetext{
"Reconhecido como ONG em 1987, o Atelier Mar vem desde essa data a actuar em programas de animação e desenvolvimento local. Assegura o funcionamento de um centro de animação cultural e tecnológica em Lajedos, Santo Antão, com programas no sector da educação básica, produção de materiais de construção civil com base nos recursos geológicos locais, transformação e alimentos e outras actividades, sobretudo ligadas à cidadania. Em São Vicente actua em duas comunidades piscatórias, São Pedro e Salamansa e no meio rural como Madeiral e Calhau, além da periferia urbana do Mindelo. Atento aos problemas ambientais e aos fracos recursos hídricos do arquipélago, o Atelier Mar também promove no sector da agricultura a introdução de novas tecnologias de produção agropecuária, programas de educação ambiental e iniciativas de resgate e reabilitação de terrenos áridos ou abandonados, para os reintegrarem no sistema produtivo das comunidades. Novas componentes como a promoção do turismo solidário e museologia comunitária estão também a ser desenvolvidas nesse contexto na perspectiva de melhoria de qualidade de vida das famílias e de projecção cultural e social das comunidades rurais e litorais na economia caboverdeana”. Disponível em: https://ateliermar.wordpress.com/. Data de acesso: 23/06/2016.
} 
em fase de finalização, nesse momento.

Defende-se a ideia de que para a condução de uma pesquisa no âmbito da Educação Artística é necessário, assim como para qualquer outro tipo de investigação, algum planejamento, mas também se procura destacar o imprevisto, as adversidades, bem como as surpresas que aparecem nesse processo como elementos fecundos para a construção ou reconstrução de conhecimentos, na medida em que tais elementos propiciam a desestabilização de noções, e portanto, propiciam o surgimento de novos saberes.

\section{Itinerários da Pesquisa}

Ao falar para as pessoas do meio acadêmico sobre o meu tema de estudos, uma escola de arte localizada na ilha de São Vicente, sempre me perguntam: Por que Cabo Verde? E com isto parecem esperar uma resposta bem fundamentada do ponto de vista teórico e metodológico sobre a minha escolha. Porém, devo confessar que para tal pergunta demorei bastante tempo na elaboração de uma resposta. Reconheço ainda que tal resposta é incompleta, provisória, na medida em que a experiência de estar entre Brasil, Portugal e Cabo Verde, sobretudo nesse último país, constituiu-se em um divisor de águas tanto para a minha vida acadêmica, quanto para a minha vida pessoal. Nesse sentido, a sensação que possuo é que demorarei ainda muito tempo, talvez anos, para compreender o quanto toda esta experiência me foi enriquecedora, estimulante e desafiadora sob os mais diversos aspectos.

Em princípio, poderia enumerar três fatores explicativos para a realização da pesquisa em Cabo Verde: o interesse por ampliar a minha formação acadêmica e cultural, centrada essencialmente na tradição ocidental. Outro fator, tendo optado por realizar o doutoramento na Faculdade de Belas Artes da Universidade do Porto e considerando a relação de estreita parceria entre essa instituição e o M_EIA, seria compreensível pensar que tal parceria tem despertado o interesse de vários doutorandos para o contexto cabo-verdiano. Por fim, e não menos importante, tomar consciência das relações históricas de proximidade entre Cabo Verde e Brasil ${ }^{4}$ revelou-se como uma instigante e prazerosa descoberta.

Estas últimas palavras me fazem lembrar algumas advertências que recebi obviamente no meio acadêmico, sobre os perigos do encantamento com relação ao tema de estudos. Lembro neste momento das sábias ponderações do mestre Vítor Martins a este respeito: "É preciso ter cuidado com o encantamento, mas é também preciso ter cuidado com a falta absoluta dele". Hoje, pensando sobre todas as adversidades que marcaram o processo de desenvolvimento da presente investigação, aspecto que será tratado mais adiante, posso afirmar com segurança que sem uma boa dose de encantamento não teria

$\infty<\infty<\infty<\infty<\infty<\infty \times \infty \times \infty \times \infty \times \infty \times \infty \times \infty$

4 Sobre as relações históricas entre Brasil e Cabo Verde, ver Pereira (2011). 
sido possível dar continuidade a empreitada de tamanha envergadura.

Assim, a escolha pelo tema de pesquisa ${ }^{5}$ vai mais além das explicações mencionadas acima, marcadas, principalmente, por elementos de caráter lógico. Arrisco a dizer que em primeiro lugar a escolha pela realização da pesquisa de campo em Cabo Verde, mais especificamente no M_EIA, localizado na ilha de São Vicente, foi um ato de ousadia, motivado, sobretudo pelo desejo quase desmedido de ampliar horizontes. Mais do que isto, hoje, começo a perceber que elementos intuitivos, ou seja, não plenamente conscientes, estiveram presentes nessa escolha.

Lembro-me de em certa ocasião, ao mencionar o projeto do trabalho de campo em Cabo Verde ter ouvido: "Mas você é rica o bastante para arcar com as despesas das viagens e da estadia por lá?” De fato, sou uma professora brasileira que tem enfrentado ao longo de toda a trajetória acadêmica inúmeros problemas de ordem material, financeira, para dar prosseguimento aos estudos. Mas algo dentro de mim palpitava dizendo que sim, que eu conseguiria ir a Cabo Verde, já que por algum motivo eu intuía que precisava ter esta experiência.

Para explicar uma intuição que poderia beirar quase ao irracional do ponto de vista acadêmico-metodológico, ou seja, da (in)viabilidade da pesquisa, Rubem Alves pode me socorrer brilhantemente, ao afirmar:

Não sei explicar como as ideias chegaram até mim. Isso é inspiração. Mas essa palavra não é permitida na linguagem da ciência. $\mathrm{O}$ cientista tem de prestar contas do caminho que seguiu até à ideia que está exibindo. Ou seja: ele tem de explicar o método... para que ela possa ser testada. O teste acontece quando outro cientista, seguindo o mesmo caminho, chega à mesma ideia. Mas não há formas de se ensinar a inspiração. Ela vem quando quer... (ALVES, 2004, p. 24).

Ouso dizer mais: ainda que um cientista trace detalhadamente todo o percurso para a realização de uma pesquisa e que fosse possível a outro investigador percorrê-lo passo a passo, os resultados alcançados de algum modo possuiriam variações, já que não só o método influi nos resultados, mas também toda a bagagem prévia, na qual um pesquisador é formado e está em constante formação: sua história de vida, formação acadêmica, ideologias, experiências profissionais, seus interlocutores ou opositores, condições materiais de existência, só para citar alguns exemplos. Todos esses fatores influenciarão na leitura de uma determinada realidade e, portanto deles não podemos nos esquivar.

$\infty<\infty<\infty<\infty<\infty<\infty<\infty<\infty<\infty<\infty<\infty$

5 Tenho consciência que o termo "Tema de Pesquisa" refere-se a algo mais abrangente, menos delimitado do que a expressão "Objeto de Pesquisa". A escolha pelo uso do primeiro em detrimento da segunda não é por acaso e tem por objetivo não apenas explicitar uma visão mais alargada a respeito da investigação desenvolvida, bem como procura revelar uma atitude de respeito para com todas as pessoas envolvidas no trabalho de campo, sobretudo os entrevistados. 
o objecto é a continuação do sujeito por outros meios. Por isso, todo o conhecimento científico é auto-conhecimento. A ciência não descobre, cria, e o acto criativo protagonizado por cada cientista e pela comunidade científica no seu conjunto tem de se conhecer intimamente antes que conheça o que com ele se conhece do real. Os pressupostos metafísicos, os sistemas de crenças, os juízos de valor não estão antes nem depois da explicação científica da natureza ou da sociedade. São parte integrante dessa mesma explicação. A ciência moderna não é a única explicação possível da realidade e não há sequer qualquer razão científica para a considerar melhor que as explicações alternativas da metafísica, da astrologia, da religião, da arte ou da poesia. A razão por que privilegiamos hoje uma forma de conhecimento assente na previsão e no controlo dos fenómenos nada tem de científico. É um juízo de valor. A explicação científica dos fenómenos é a auto-justificação da ciência enquanto fenômeno central da nossa contemporaneidade. A ciência é, assim, autobiográfica (SANTOS, 2010, p.19).

Considerando o caráter autobiográfico da ciência apontado por Santos, sinto-me a vontade para citar parte de uma anotação pessoal, datada de março de 2015. Esta pode fornecer algumas pistas sobre a amplitude, importância e impactos causados em meu modo de pensar e refletir sobre o mundo a partir do período de permanência em Cabo Verde, bem como sobre a necessidade desta experiência de uma maneira mais ampla:

No dia 01 de outubro de 2014, em viagem de regresso de Cabo Verde ao Brasil, desembarquei no aeroporto de Confins, na cidade de Belo Horizonte, capital do estado de Minas Gerais. Mas foi somente no início do ano de 2015 que tomei consciência do grave problema de abastecimento de água para as cidades da região sudeste, região esta onde está localizada a minha cidade. Apesar das lideranças políticas atribuírem o problema à falta de chuva nos dois últimos anos, o desmatamento desenfreado, sobretudo, nas zonas de mananciais; o desperdício inconsequente; o agronegócio; bem como a urbanização mal planejada; foram alguns dos principais agentes causadores deste triste e lamentável cenário. O Estado de Minas Gerais, considerado como berço das águas por possuir nascentes que formam os principais rios das regiões sudeste e nordeste, participava deste quadro. E embora, não se possa dizer que este fosse um quadro surpreendente $^{6}$, muitos de nós, acostumados à abundância, e infelizmente, ao

$\infty<\infty<\infty<\infty<\infty<\infty<\infty<\infty<\infty<\infty<\infty<\infty$

6 Já nas últimas décadas, ambientalistas vinham alertando para os problemas hídricos que enfrentaríamos 
consumo inconsequente, foram pegos de surpresa. Refleti sobre as voltas da vida, nos caminhos que me levaram a Cabo Verde... Pensei neste país, desfavorecido pela natureza em termos de água e em sua histórica luta para reverter tal situação. Nas crises de fome enfrentadas pelos cabo-verdianos em diversos momentos da história do país, em consequência da escassez de chuvas, crises que muitas vezes levaram a morte de mais da metade da população do país. Em contraste, refleti sobre o caminho totalmente inverso trilhado por nós brasileiros: um país privilegiado do ponto de vista de riquezas naturais, outrora abundante de um dos bens mais preciosos, a água, e, no modo como toda esta riqueza tem se perdido. Foi duro encarar esta realidade. Posso dizer que estes pensamentos me abalaram de maneira profunda. A imagem do conjunto Babilônia ${ }^{7}$, com seu pomar e horta, bravamente construídos em Lajedos ${ }^{8}$, região relativamente árida da ilha cabo-verdiana de Santo Antão, tornaram-se para mim como uma referência fundamental. Percebi que teria muito mais para aprender com a minha investigação do que eu poderia imaginar. E de certa forma, posso dizer que tal perspectiva me forneceu algum ânimo e me alimentou as esperanças: o meu tema de pesquisa me proporcionaria reflexões de fundamental importância para o justo momento em que estamos vivendo no Brasil (Anotações pessoais).

Mais tarde, percebi que a questão de fundo tratada no trecho acima está além dos problemas enfrentados pelo Brasil na atualidade, mas coloca em cheque todo um modelo de desenvolvimento pautado no capitalismo predatório e que põe em risco todas as formas de vida no planeta. Segundo dados da ONU até a década de 2050 cerca de

no Brasil, em um futuro próximo, caso não fossem tomadas medias não somente preventivas, mas, sobretudo, corretivas a respeito da situação. Um dado importante, fornecido informalmente pelo médico e ambientalista brasileiro, Apolo Heringer-Lisboa, é que os índios foram percebendo a diminuição dos animais e do volume dos rios, o assoreamento desses últimos, desde o avanço da colonização portuguesa.

7 Situado em Lajedos, Concelho do Porto Novo, na Ilha de Santo Antão, "o conjunto integra um pomar e duas residências, restaurante e bar. Para além de servir a comunidade de Lajedos terá ainda dois programas complementares. Apoiar a residência de estudiosos e artistas nacionais e internacionais que visitam a região em trabalhos de criação artística ou de investigação científica; colaborar em iniciativas de outras organizações parceiras nos domínios da formação em tecnologias e gestão do turismo rural". "A conquista e reabilitação de terrenos devolutos e improdutivos, o estímulo à produção agrícola biológica bem como o recurso a novas tecnologias de rega e de cultivo, tiveram importância capital na motivação e criação do projecto. O edifício, construído com materiais locais e utilizando soluções construtivas alternativas, quer-se que tenha efeito demonstrativo sobre a prática de técnicas de construção sustentáveis, tanto sob o ponto de visto estético como ambiental que, por si só, poderá tornar-se numa marca da localidade". Disponível em: http://babilonialajedos.blogspot.com.br/2015/05/o-conjunto-integra-um-pomar-e-duas.html. Data de acesso: 2306/2016.

8 Comunidade localizada na Ilha de Santo Antão, Cabo Verde. 
metade da população mundial sofrerá com escassez de água.

Em uma das viagens a Cabo Verde ouvi o nome de um documentário caboverdiano intitulado "Com quase nada". Infelizmente, não tive acesso ao documentário, mas confesso que apenas a menção ao título foi algo extremamente provocador no melhor sentido do termo.

Durante a minha permanência na ilha de São Vicente, em algumas curtas estadias na belíssima ilha de Santo Antão, bem como por meio da breve passagem pela ilha do Sal, conversei com inúmeras pessoas: homens, mulheres, idosos, jovens, crianças, trabalhadores dos mais diversos setores. Com essas pessoas estabeleci vínculos a ponto de ouvir confissões muito pessoais sobre as suas dificuldades, desafios, anseios e sonhos. Os altos índices de desemprego, sobretudo entre os mais jovens, o piso salarial baixíssimo para aqueles que conseguiram um trabalho, dentre outros fatores, colocam desafios cotidianos às populações das ilhas. Foi com muita comoção, por exemplo, que ouvi de um taxista: "O dinheiro que ganho com o meu trabalho não dá sequer para comprar um medicamento na farmácia quando preciso”... Eu teria inúmeros outros exemplos para fornecer a respeito dos desafios cotidianos enfrentados pela maior parte das populações das ilhas, a partir dos diálogos com os cabo-verdianos. Depoimentos fortes, comoventes, mas que também desafiam a nossa forma de estar e de pensar sobre o mundo. Porém, fico por aqui a fim de seguir com o desenvolvimento do meu raciocínio.

Até o presente momento, eu não tenho dúvida de que deve ser realmente difícil desejar o alívio para uma doença, saber que existe um medicamento para isto, mas não poder adquiri-lo. Porém, também me pergunto: será mesmo que este modelo de desenvolvimento baseado na produção e consumo desenfreados constitui-se na única ou na melhor forma de vida para nós seres humanos? E mais: aqueles que vivem em países, regiões ou zonas consideradas como periféricas, estão de fato, sob todos os aspectos, em situação de desvantagem? São mesmo subdesenvolvidos?

Durante os períodos de estadia em Cabo Verde a expressão "com quase nada", ressoava e continua ainda hoje ressoando em minha mente. Neste ponto devo fazer uma confissão, talvez a mais importante a respeito desta investigação: na verdade, fui a Cabo Verde muito mais para aprender do que para enquadrar, descrever, analisar, interpretar ou traçar recomendações a respeito de algum assunto, embora em determinado momento isto tenha sido feito e, de certa maneira, tenha possibilitado a escrita da investigação do doutorado. Este é um primeiro aspecto que gostaria de deixar bem claro a respeito da minha metodologia de trabalho.

Nesse sentido, posso dizer que uma das minhas principais ferramentas para a condução da investigação foi a escuta atenta e atenciosa não só das pessoas diretamente envolvidas com o M_EIA, mas das diversas pessoas com as quais convivi, sobretudo na ilha de São Vicente. Desta escuta cuidadosa, interessada, foram estabelecidos vínculos de confiança mútua entre "pesquisadora" e "depoentes". A partir disso, tive acesso as mais diversas percepções a respeito do meu campo restrito de pesquisa, bem como do contexto de Cabo Verde de maneira mais abrangente. 
Talvez o discurso desenvolvido até esse ponto possa ser considerado como um discurso romântico, ou sem um maior embasamento científico. Assim, recorro a Chantal Mouffe, teórica consagrada no campo da ciência política. Ao enumerar alguns tipos de arte crítica capazes de desestabilizar a ordem hegemônica a autora cita quatro possibilidades, dentre elas: A “arte como experimentação utópica” ou “intentos de imaginar formas de vida substitutivas: sociedades construídas em torno de valores opostos ao ethos do capitalismo tardio" (MOUFFE, 2007, p. 69).

Em uma conversa com Leão Lopes ${ }^{9}$, reitor do M_EIA, criador do Atelier Mar e do Complexo da Babilônia, explicava-me sobre um dos modos pelos quais trabalham a sustentabilidade no restaurante da Babilônia. A respeito dos pratos servidos no local, Leão Lopes, afirmou, não exatamente com estas palavras: - Decidimos observar a quantidade média de arroz que uma pessoa consome. Desta observação, concluímos que poderíamos servir os pratos com uma quantidade menor desse grão o que evitaria desperdícios e nos possibilitaria ainda diminuir o preço da refeição. Admirada, exclamei: - Isto é ética! Ao que Leão Lopes respondeu: - Isto é mais do que ética, é a única possibilidade!

De volta ao Brasil e, na medida em que, eu me inteirava melhor a respeito dos graves desafios ambientais que a população mundial vem enfrentando, quer queira, quer não queira olhar para eles, as palavras de Leão Lopes passaram a fazer cada vez mais sentido para mim. E de fato, pude refletir sobre o caráter de resistência aos valores do capitalismo tardio desenvolvido nos vários trabalhos realizados pelo M_EIA e pelo Atelier Mar no contexto cabo-verdiano, tendo a arte como uma de suas principais ferramentas ou estratégias.

Tendo feito essas considerações iniciais a respeito da minha imersão e interesse pelo contexto cabo-verdiano, nomeadamente pelo M_EIA, passo, a seguir, a delinear a trajetória metodológica construída para a realização da presente pesquisa, sem a pretensão de que tal narrativa possa constituir-se em um passo a passo para a validação de supostos resultados encontrados. Por outro lado, com a devida licença poética que a realização do doutorado em Educação Artística me permite, espero que o testemunho deste caminhar constitua sim em inspiração para outros pesquisadores.

A este respeito gostaria de fazer uma última consideração, uma espécie de agradecimento ao escritor e jornalista nascido em Luanda, António Tomás, autor do livro "O Fazedor de Utopias: uma biografia de Amílcar Cabral”. Tendo passado por inúmeras

$\infty<\infty<\infty<\infty<\infty<\infty<\infty<\infty<\infty<\infty<\infty<\infty$

9 "Nasceu em Santo Antão em 1948. Doutorado pela Universidade de Rennes II, França, e diplomado em pintura pela Escola Superior de Belas-Artes de Lisboa, é membro fundador do Instituto Universitário de Arte, Tecnologia e Cultura (M_EIA), onde desempenha as funções de reitor. Tem desenvolvido, ao longo dos anos, uma intensa atividade nos domínios da criação artística que passam pela literatura, as artes plásticas, o design e o cinema. Assina a primeira longa-metragem cabo-verdiana com o filme 'Ilhéu de Contenda'. Autor e realizador de inúmeros documentários, dos quais se destacam 'Bitu' e, mais recentemente, 'S. Tomé - Os Últimos Contratados', desempenhou ainda os cargos de Deputado Nacional e de Ministro da Cultura”. É também criador da ONG cabo-verdiana denominada Atelier Mar. Disponível em: http://www.nosgenti. com/?p=926. Data de acesso: 23/06/2016. 
dificuldades para a realização da presente tese e a beira de experimentar uma tristeza quase inerte, a leitura da introdução da referida obra foi de fundamental importância para a renovação das minhas esperanças e para o fortalecimento da decisão em continuar firme diante do meu intento. Tomás relata de maneira sucinta, mas enfática, os inúmeros desafios que foi preciso enfrentar para a realização da investigação que daria origem a sua obra, a começar pelo primeiro projeto de pesquisa que elaborou, nomeado por ele mesmo como medíocre. Além disso, o autor conta sobre a necessidade das viagens a Cabo Verde e a Portugal com recursos parcos e o fato de ter precisado dormir muitas vezes em sofás da casa de amigos por falta de condições financeiras para pagar hospedagens. Apesar de todas estas dificuldades e do aparente fracasso inicial na realização do primeiro projeto de pesquisa, Tomás nos brinda com uma obra de grande interesse a respeito de Amílcar $\mathrm{Cabral}^{10}$, personalidade fundamental para a compreensão do processo histórico, político e da luta pela Independência dos países de Guiné Bissau e Cabo Verde, bem como da influência deste contexto para o processo de Independência de outros países africanos.

Eu estava em Portugal muito desanimada, terminando o primeiro ano letivo do doutoramento, em 2014, época em que li a obra de Antônio Tomás. Meu desânimo devia-se a uma desagradável situação trabalhística que me pegou de surpresa logo nos primeiros meses em que eu havia chegado a Portugal para realizar o doutoramento.

Parti para Portugal em janeiro de 2014 com uma licença remunerada da Universidade do Estado de Minas Gerais (UEMG) para capacitação profissional, direito até então garantido pelo seu Estatuto. A minha pretensão era permanecer o tempo integral do curso entre Portugal e Cabo Verde.

Até a presente data eu possuía nove anos como professora na UEMG, tendo sido efetivada no ano de 2007 através da Lei Complementar (LC) 100/2007, de Minas Gerais. Por meio da Lei 100 cerca de 78 mil servidores do estado foram efetivados sem concurso. No dia 26 de março de 2014, o Supremo Tribunal Federal declarou a referida lei como inconstitucional. Desta maneira, perdi todos os meus direitos como professora da universidade, inclusive o direito a licença remunerada.

O grande problema é que eu estava em outro país, sem qualquer informação oficial sobre a minha situação, ou seja, sem saber a partir de qual data eu deixaria de receber o meu salário, única fonte de renda que eu possuía para me manter no exterior.

Dada a situação de instabilidade profissional, como planejar uma pesquisa?

Voltando ainda ao primeiro semestre do ano de 2014, não tendo obtido informações oficiais do setor de Recursos Humanos da UEMG, fiz contato direto com os diretores da unidade da Universidade onde ainda atuo, porém, atualmente em regime precário

$\infty<\infty<\infty<\infty<\times<\times<\times<\times<\times<\infty<\times<\infty$

10 "Amílcar Cabral nasceu em Bafatá, Guiné-Bissau, a 12 de Setembro de 1924 e foi morto a 23 de Janeiro de 1973. Filho de Juvenal Cabral e Iva Pinhel Évora, Cabral foi poeta, agrónomo, fundador do PAIGC e 'pai' da independência conjunta de Cabo Verde (5 Julho de 1975) e Guiné-Bissau (oficialmente a 10 Setembro de 1974)". Disponível em: http://noticias.sapo.cv/info/artigo/1005005.html. Data de acesso: 23/06/2016. 
de contratação. Segundo meus colegas de trabalho era previsto que um concurso para preenchimento dos cargos dos ex-efetivados acontecesse em meados de outubro daquele ano, isto é, ainda no ano de 2014. Com base nestas informações, tracei o seguinte plano: passar pela qualificação no doutoramento da FBAUP no mês de junho e, adiantar a minha ida a Cabo Verde para a recolha de dados, de novembro/dezembro de 2014, para o início de julho desse mesmo ano. E assim o fiz, permanecendo em Cabo Verde, ilha de São Vicente, pelo período de quase três meses - julho, agosto e setembro. Essa foi a minha segunda viagem ao país, pois lá estive ainda em fevereiro de 2014, durante uma semana.

A primeira viagem a Cabo Verde consistiu em uma aproximação inicial com o campo de estudos. Apesar da curta estadia, já nesta ocasião pude estabelecer contato com Leão Lopes, com os professores do M_EIA residentes na ilha, bem como com vários alunos. Neste momento, realizei apenas conversas informais com muitas destas pessoas a fim de captar algumas impressões e informações iniciais sobre o meu tema de estudos que, a propósito, estava ainda sendo delineado. Também tive a oportunidade nesta ocasião de fazer um fascinante passeio por algumas regiões da ilha de Santo Antão coordenado pelo professor Leão e acompanhada dos professores da Faculdade de Belas Artes da Universidade do Porto (FBAUP), José Paiva e Joana Paradinho, dos brasileiros Madalena Zaccara, Paulo Emílio e Dori Nigro, bem como dos alunos do primeiro ano matriculados no M_EIA. A experiência da travessia da ilha de São Vicente para a ilha de Santo Antão nas águas cabo-verdianas turbulentas do mês de fevereiro, bem como contemplar o céu e mar em tons de azul belíssimos e, ainda saborear os ventos na parte externa da embarcação foi uma das experiências mais encantadoras e marcantes que vivi.

De volta a Portugal, a aula aberta ministrada por Leão Lopes na FBAUP, com o tema "M_EIA, uma experiência de Educação Artística no contexto preciso de Cabo Verde", no dia 17 de junho de 2014, foi de suma importância para começar a delinear os contornos do foco de interesse da pesquisa, elemento que também foi fundamental para uma primeira elaboração dos roteiros de entrevistas a serem realizadas não somente com o próprio Leão, mas com outros sujeitos envolvidos com o M_EIA. Da fala de Leão Lopes, na aula no Porto, fica patente a noção da Escola como um campo aberto de experiências, pesquisas e atuação comprometido com o social, campo este muito mais vasto do que o próprio M_EIA. Tal noção, portanto iria constituir-se no fio condutor da presente investigação.

Conforme sinalizado anteriormente, a data da segunda viagem a Cabo Verde esteve condicionada a um grande contratempo com relação a minha situação trabalhística no Brasil. Eu pretendia retornar a São Vicente apenas no final do ano de 2014, pois considerava que até lá estaria mais preparada do ponto de vista teórico para uma imersão de fato no terreno de pesquisa. Mas, motivos de causa maior colocaram-me o desafio de partir rumo a São Vicente no início do mês de julho de 2014.

Entretanto como bem disse Mário Osório Marques (2006, p. 30): "Escrever é o começo dos começos. Depois é a aventura". Naquela ocasião eu mal havia começado a 
escrever sobre o meu tema de pesquisa, isto é, a aventura sequer poderia ter começado...

Nesse sentido, de maneira poética, Marques recomenda àqueles que estão começando a trilhar os caminhos de uma investigação e anseiam pelo tão evocado "amparo" teórico:

Uma mochila com poucos pertences do ofício artesanal, uma bússola, vale dizer um título que resuma o problema, ou tema, e a hipótese de trabalho. Uma lâmpada para iluminar os caminhos à medida que apaga a luz do dia. É desse jeito que a teoria ilumina e conduz a prática, mas só quando a própria prática a deslocou para a situação a que deve servir e produzir adequada. Por isso, de saída não se pode saber quais nossos interlocutores. Surgirão eles durante a caminhada. Isso faz parte da aventura (MARQUES, 2006, p. 30).

Assim, munida das reflexões elaboradas a partir da aula de Leão Lopes no Porto, de algumas poucas, mas importantes obras que tratam de temas mais gerais a respeito do contexto cabo-verdiano, emprestadas pelo professor José Paiva ${ }^{11}$, tais como "História da Guiné e Ilhas de Cabo Verde" (1974) e o referido livro sobre a biografia de Amílcar Cabral, de uma câmera de filmagem emprestada pela minha orientadora da Universidade de Porto, a professora Dr. ${ }^{\text {a }}$ Teresa Medina, bem como de um gravador, parti novamente rumo ao campo de estudos.

Durante os três meses de permanência nas ilhas, paralelamente a leituras dos livros emprestados pelo professor Paiva e da realização de fichamentos, também fiz uma carteira na biblioteca municipal do Mindelo para o acesso a obras da literatura cabo-verdiana ${ }^{12}$. Nesta época li "Chiquinho", "Famintos”, a coleção quase completa da Revista "Claridade" e da Revista "Ponto e Vírgula". Li ainda obras da literatura infanto-juvenil escritas por Leão Lopes, mas cujas referências bibliográficas completas não encontrei. Assim, lamentavelmente deixo de citá-las nesse ensaio. Quanto à importantíssima obra de Manuel Lopes, "Os Flagelados do Vento Leste", eu já a havia lido no final do ano de 2013, antes mesmo de partir para Portugal. Essa última obra pode ser encontrada na Biblioteca Pública Municipal Luiz de Bessa, na cidade de Belo Horizonte.

$\infty \times<\times<\times<\times<\times<\times<\times<\times<\times<\times<\infty$

11 José Carlos de Paiva e Silva: Diretor do curso Doutoral em Educação Artística da Universidade do Porto. Diretor da faculdade de Belas Artes dessa mesma universidade. Membro do movimento intercultural IDENTIDADES, criado no ano de 1996, na cidade do Porto. Tem como objetivo desenvolver "uma teia de relacionamento intercultural com instituições educativas, artísticas e culturais, com comunidades envolvidas em processos de desenvolvimento colaborativo e de afirmação de identidade, com artistas, professores e cidadãos, numa ampla geografia que se alarga por Moçambique, Cabo Verde, Brasil e Portugal”. Disponível em: http://identidades.eu/node/21. Data de acesso: 23/06/2016.

12 Assim como no Brasil, as obras de literatura constituem-se em elemento de fundamental importância para a compreensão da formação de uma identidade nacional no processo de independência, em Cabo Verde, país que também foi colônia de Portugal, verifica-se o mesmo. Desta maneira, considerei que o contato com a literatura cabo-verdiana seria importante para uma aproximação mais ampla com o meu contexto de investigação. 
Desta maneira, a bagagem inicial era pequena, mas, paulatinamente, leituras não previstas ou que, aparentemente, não estavam diretamente ligadas ao meu tema de estudos, foram sendo realizadas durante aqueles três meses em São Vicente.

Referindo-nos agora à nossa bibliografia, não cabe ela na mochila. Não pode, nem deve, ser de início muito abundante, senão nos amarraria, mais peso do que auxílio na caminhada. Não há porque tanto precaver-se. Em cada lugar de parada, cada acampamento, encontraremos gente nova. Basta a fumacinha do acampamento para que apareça companhia. Havia, numa cidade vizinha, um cidadão que em seu aniversário se instalava no centro da praça principal, com panelas e panelões de feijoada. Imediatamente surgiam os amigos, cada qual com seu prato e colher. Vinha o bispo, vinha o prefeito, vinham os colegas de trabalho, vinham os parentes e os amigos todos, aos magotes, cada qual com seus próprios amigos e estes, por sua vez com os amigos seus, de penetras. A festa era geral, a alegria e as conversas corriam soltas. Às vezes, um grupo aqui outro acolá cercavam determinado assunto, terreno propício às discussões mais acaloradas (MARQUES, 2006, p.30-31).

Se por um lado, a minha formação acadêmica anterior me conduzia a necessidade de controle e delimitação, precipitada, da definição do "objeto" de estudo, do quadro teórico de referência, bem como da metodologia a ser adotada, por circunstâncias da vida, foi preciso entregar-me ao improviso e ao inesperado. E, se por um lado, este foi um aprendizado, sob certos aspectos, angustiante, durante vários momentos na realização do doutoramento, por outro lado, o sabor da aventura acabou por constituir-se em um interessante estímulo tanto intelectual quanto para a tomada de decisões a respeito de situações bastante concretas. Assim, posso afirmar que um dos importantes ganhos de todo este processo foi a potencialização da minha criatividade em diversos sentidos.

Indo mais adiante com essa reflexão, creio poder afirmar que a metodologia da tese, construída a partir do imprevisível, do instável, isto é, de muitas situações impossíveis de serem controladas, relaciona-se ao próprio assunto (conteúdo) apresentado, na medida em que se discute uma escola "não escola,"13 e toma-se como apoio teórico

$\infty<\infty<\infty<\infty<\infty<\infty<\infty<\infty<\infty<\infty<\infty<\infty$

13 O termo escola "não escola”, utilizado pelos criadores do M_EIA para designá-la, pretende tensionar, problematizar o espaço ocupado por uma escola de arte, que se por um lado é regulamentada e reconhecida juridicamente pelo Ministério da Educação cabo-verdiano, por outro lado, procura demarcar uma atuação mais ampla da escola não apenas nos espaços formais, mas também em espaços informais, bem como o estabelecimento de uma relação de proximidade entre as necessidades das populações das ilhas do país e os projetos desenvolvidos pela escola. Nessa perspectiva, ao mesmo tempo em que a escola procura adequarse às exigências legais determinadas pelo Ministério da Educação, a escola também busca continuamente alimentar-se dos desafios enfrentados pela sociedade cabo-verdiana em seu dia a dia como fonte importante para a seleção dos conteúdos curriculares, para o estudo dos modos pelos quais esses conteúdos são desen- 
autores tais como Atkinson para o qual a educação deve acolher o imprevisível ou direções inesperadas na aprendizagem. Nesse sentido, pode-se afirmar que a metodologia de trabalho construída para a realização da investigação corrobora com a noção de Educação Artística aqui defendida, marcada pelo posicionamento de rupturas com o estado de coisas instituído pelo poder hegemônico, ou seja, com a ruptura de construções fixas da subjetividade" para que estas "novas formas de "se tornar" (becoming) possam irromper e se tornar aparentes." Em síntese, acredito ter ocorrido uma adequação ou casamento entre o conteúdo da investigação e as formas pelos quais ela foi desenvolvida (metodologia). De fato, os ganhos decorrentes de todo o processo de realização da investigação foram enormes tanto quanto os desafios, pois há que se ter ou desenvolver flexibilidade, certa bagagem teórica e prática, coragem e abertura para o não controlável ou aquilo que ainda não se pode adivinhar, porque carrega justamente as marcas do novo! Eis a aventura de se construir uma tese entre Brasil, Portugal e Cabo Verde em uma situação de precariedade profissional.

Relacionando o percurso realizado para o desenvolvimento deste trabalho ao contexto cabo-verdiano, a própria noção de precariedade como algo exclusivamente negativo pode ser questionada, assunto que poderia dar margem a outras tantas investigações no terreno da Educação Artística, área de conhecimento acostumada a lidar com a precariedade, pois tradicionalmente marginalizada no campo educacional em países tais como Brasil e Cabo Verde. Procurarei retomar tais reflexões no tópico "Considerações finais" deste texto.

Para que o presente ensaio não se torne um "Livro sem fim" (ALVES: 2004), entretanto, passo, a partir deste momento, a explicitar de maneira mais objetiva e sucinta alguns aspectos metodológicos para a recolha de dados.

\section{0 passo a passo da metodologia construída para a investigação}

As leituras mais amplas sobre o contexto cabo-verdiano nos três meses de estadia na ilha de São Vicente foram realizadas durante as noites ou em alguns intervalos entre um encontro e outro com professores e alunos do M_EIA, além das conversas com o Leão Lopes. Durante aqueles meses a escola estava em períodos de férias, mas dava-se continuidade a alguns projetos envolvendo alunos e professores da escola. Assim, pude acompanhar o desenvolvimento dos mesmos de perto. Fato que me propiciou o contato com algumas práticas em Educação Artística desenvolvidas pelo M_EIA. A partir da observação direta desses projetos construí notas de campo que mais tarde me auxiliaram no entendimento das dinâmicas da escola.

volvidos, e ainda em uma preocupação constante em extrapolar o processo de ensino-aprendizagem para além de seus muros, proporcionando assim ricas trocas entre a escola e as comunidades locais. 
Outro ponto de fundamental importância foi o da realização das entrevistas. Estas aconteceram predominantemente no edifício do M_EIA ou nas imediações da escola, conforme critério e disponibilidade dos entrevistados. Foram realizadas duas entrevistas com Leão Lopes, reitor da escola e figura de fundamental importância para a sua criação, organização e gestão, bem como marca decisiva nas concepções de Educação Artística e nas metodologias de trabalho presentes na instituição.

Nesse período, havia na escola, seis professores residentes na ilha de São Vicente. Dos seis professores, quatro deles foram entrevistados. Já com os dois outros professores, aconteceram inúmeras conversas informais, registradas em notas de campo, devido ao grau de proximidade estabelecido entre a pesquisadora e eles. Nesse sentido, considerou-se desnecessário a realização de uma entrevista formal com os dois últimos professores citados.

No que se refere aos alunos da escola, foram formalmente entrevistados, na ocasião, dez deles, tendo por critério a participação em projetos que estavam em curso naquele período de férias escolar. Outro critério de seleção desse grupo de entrevistados foi à indicação de colegas ou de professores, dos alunos que tiveram um maior nível de envolvimento com os projetos. Este nível de envolvimento foi definido pelas pessoas que fizeram tais indicações, tendo por critério, sobretudo a assiduidade e, em alguns casos, a liderança na condução dos projetos. Porém, também considerei importante entrevistar alunos que simplesmente participaram de alguns dos projetos, independentemente do grau de envolvimento com eles, a fim de captar uma maior multiplicidade de pontos de vista sobre o M_EIA e seus projetos pelos discentes. Importante ressaltar que, na medida em que a escola não se restringe ao seu espaço físico, muitos projetos realizados pelo M_EIA ou em parceria com essa instituição nas ilhas, não são suspensos no período de férias escolares. Também com os alunos da escola foram realizadas várias conversas informais.

Além disso, foi entrevistada a coordenadora do Atelier Mar na ocasião, Mami Estrela, bem como um colaborador da ONG, dada a relação umbilical entre ambas as instituições. Na ilha de Santo Antão, foi entrevistada uma pessoa que lidera um dos projetos de desenvolvimento sociocomunitário em Lajedos implantado em parceria com o Atelier Mar.

Por fim, mas não menos importantes foram entrevistadas cinco pessoas de uma localidade da Ilha de São Vicente, tendo por critério a participação dessas pessoas em uma intervenção do M_EIA em parceria com o Atelier Mar na comunidade.

$\mathrm{O}$ roteiro das entrevistas combinou questões fechadas e abertas. Foram elaboradas questões que procuravam captar as diferentes percepções dos sujeitos acerca das seguintes grandes temáticas: concepções de Educação Artística, de arte, de investigação aplicada $^{14}$, de investigação participativa e de desenvolvimento local presentes no M_EIA;

$\infty<\infty<\infty<\infty<\infty<\infty \times \infty \times<\infty<\infty<\infty<\infty<$

14 Segundo entrevista concedida pelo diretor do M_EIA, Valdemar Lopes, em janeiro de 2016, a concepção de pesquisa aplicada, um dos importantes eixos norteadores do trabalho desenvolvido pelo M_EIA, 
bem como as interações entre a escola e a comunidade na realização dos projetos de desenvolvimento local.

Os entrevistados assinaram um termo de cessão das entrevistas, mas salvo algumas poucas exceções, optou-se por não divulgar os nomes dos entrevistados, a fim de preservar seu anonimato.

Durante este período também coletei fontes documentais tais como o Dossiê do M_EIA, seus programas de ensino, livros utilizados como referência pelos professores em suas aulas, textos escritos pelo Leão Lopes a respeito da escola, da arte, da educação e do artesanato em Cabo Verde, fotografias, dentre outras.

Pode-se afirmar nesse sentido que a metodologia construída para a realização da pesquisa aproxima-se dos Estudos de Caso em Educação, na medida em que procurou "focalizar um fenômeno particular, levando em conta seu contexto e as suas múltiplas dimensões". O aspecto unitário foi valorizado, a investigação de apenas uma escola, mas com o intuito de desenvolver uma análise situada e em profundidade (ANDRÉ, 2013, p. 97).

Stake (1995), citado por André (2013, p. 98), discrimina três tipos de estudo de caso. São eles: o intrínseco, o instrumental e o coletivo:

O intrínseco é aquele em que há interesse em estudar aquele específico caso. Por exemplo: uma experiência inovadora, que vale a pena ser investigada para identificar quais os elementos que a constituem, o que a faz tão distintiva, que recursos foram necessários para atingir este nível, que valores a orientam, que resultados obteve e assim por diante. Naturalmente, a pesquisa exigirá uma multiplicidade de fontes de dados, de métodos e procedimentos de coleta e análise de dados. O estudo de caso instrumental é aquele em que o caso não é uma situação concreta, mas uma questão mais ampla, como, por exemplo, a incorporação de uma política no cotidiano escolar. Pode-se escolher uma escola qualquer que vai ser a base para investigar como essa política é apropriada pelos atores escolares. O estudo de caso é coletivo quando o pesquisador escolhe diferentes casos, intrínsecos ou instrumentais, para estudo.

Considerando a singularidade do M_EIA, uma escola 'não escola', e que foge, portanto as concepções tradicionais do que seja uma escola de arte, bem como extrapola

\footnotetext{
"está intimamente ligada com uma ação transformadora da realidade que nos envolve, tanto numa perspectiva conceitual, como material, visando um preparar pessoas, nossa instituição como entidade também que cresce, que aprende, os alunos como os novos atores que devem ser preparados para intervirem numa realidade cada vez mais complexa. E isso só é possível nesta lógica duma relação muito próxima com a realidade, fazendo com que as nossas ações, ou o que nos move como instituição educacional tenha como referente problemas concretos, ter como referente as várias realidades nas quais nos cruzamos, as pessoas, os seus problemas".
} 
seu domínio de atuação para além das fronteiras do que convencionalmente se entende como o papel de uma escola de arte, pode-se afirmar que o estudo de caso ora desenvolvido classifica-se como o intrínseco.

Contudo, no desenvolvimento da metodologia de trabalho, não procurei me ater a uma tipificação da pesquisa, sobretudo de maneira prematura. Tal nome, ora identificado, o do estudo de caso intrínseco, foi mencionado por avizinhar-se aos contornos que a presente investigação acabou por assumir e não o contrário.

Foi por esta época que conheci a professora Aracy Martins da Universidade Federal de Minas Gerais. Embora tivéssemos residência fixa na mesma cidade, Belo Horizonte, foi em Cabo Verde que nos conhecemos. Logo na segunda semana em que eu estava em São Vicente, no mês de julho de 2014, aconteceu o "XI Congresso da AIL", Associação Internacional de Lusitanistas. A Universidade de Cabo Verde (Uni-CV) consistiu na instituição responsável pela organização do evento, mas como o prédio do M_EIA, o Liceu Velho, sediou o congresso, resolvi acompanhar como ouvinte algumas conferências e apresentações de pesquisas, dentre elas, a da professora Aracy Martins a respeito do crioulo cabo-verdiano na educação formal. A partir desse encontro estreitamos os laços acadêmicos, laços esses que seriam mais tarde de fundamental importância para o estabelecimento do Acordo de Cotutela entre a Universidade do Porto e a Universidade Federal de Minas Gerais. A Cotutela foi a saída encontrada diante da minha impossibilidade de permanecer em Portugal para a continuidade do doutoramento, devido a reviravolta ocorrida na minha situação trabalhística no Brasil, conforme relatado anteriormente.

Com o intuito de aproximar ainda mais do cotidiano das populações das ilhas, de seu clima sociocultural, participei do dia a dia de algumas famílias, com as quais fiz amizade, participei de festas de aniversário, almoços, cafés, passeios etc. Também fui ao famoso festival de música na Baía das Gatas, evento de grande repercussão na ilha de São Vicente. Conversei com garçons, taxistas, marinheiros, vendedores de frutas e verduras nas ruas, senhoras nas pracinhas ou na praia da Lajinha ${ }^{15}$, com seus filhos ou netos. Peguei carona na ilha de Santo Antão para voltar de Lajedos a Porto Novo ${ }^{16}$. Na maior parte destas situações fui acolhida pelos cabo-verdianos de maneira calorosa e respeitosa. Ao escutar um pouco da história de cada uma dessas pessoas fui presenteada com um pouquinho delas, bem como doei um pouco de mim.

As abordagens qualitativas de pesquisa se fundamentam numa perspectiva que concebe o conhecimento como um processo socialmente construído pelos sujeitos nas suas interações cotidianas, enquanto

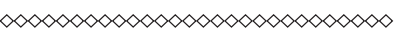

15 "A Praia da Lajinha é uma das praias mais frequentadas por toda a população do Mindelo. Situada no centro da cidade, permite maior acessibilidade das pessoas e está localizado dentro da Baía do Porto Grande". Disponível em: http://asemana.publ.cv/spip.php?article94076. Data de acesso: 23/06/2016.

16 Concelho da ilha de Santo Antão. 
atuam na realidade, transformando-a e sendo por ela transformados. Assim, o mundo do sujeito, os significados que atribui às suas experiências cotidianas, sua linguagem, suas produções culturais e suas formas de interações sociais constituem os núcleos centrais de preocupação dos pesquisadores. Se a visão de realidade é construída pelos sujeitos, nas interações sociais vivenciadas em seu ambiente de trabalho, de lazer, na família, torna-se fundamental uma aproximação do pesquisador a essas situações (ANDRÉ, 2013, p. 97).

Ao final dos três meses, parti de Cabo Verde ansiosa para retornar ao Brasil e reencontrar, após nove meses de ausência, a minha família e amigos, mas também com o coração apertado pela "sodad" ${ }^{17}$ dos amigos deixados para trás.

Ao chegar ao Brasil, vivi um período de muita instabilidade: eu havia voltado para a minha cidade para fazer o concurso na universidade onde trabalho, mas o edital, publicado no final do ano de 2014 era suspenso de tempos em tempos. A situação arrastava-se, fato que me gerava ansiedade, angústia e a impossibilidade de prever nova ida a Cabo Verde ou a Portugal. Eu me sentia de pés e mãos atados e embora tivesse coletado muitos dados em Cabo Verde sobre os quais trabalhar, a escrita da tese era lenta, sempre interrompida pela necessidade de estudar para um concurso que ninguém sabia dizer ao certo quando aconteceria. A situação me deixava exaurida, porém minha capacidade de resiliência não estava completamente vencida.

Convidada pela professora Aracy Martins, eu participava de Congressos, Seminários e outras atividades relacionadas a Cabo Verde por meio do "Núcleo de Estudos e Pesquisas em Educação, História, Letras e Artes: Diversidade Sociocultural, Relações Étnico-raciais em Países de Língua Portuguesa" (NEPEHLA), da Universidade Federal de Minas Gerais, núcleo do qual passei a ser membro integrante.

Ciente das minhas dificuldades profissionais, o Acordo de Cotutela foi apresentado pela Coordenadora do Programa de Pós-Graduação da Faculdade de Educação da UFMG, Maria da Conceição Fonseca, como solução para o impasse de não poder continuar o doutoramento presencialmente na FBAUP.

Após meses bastante difíceis, consegui tomar novo fôlego, e finalmente organizar outra ida a Cabo Verde em janeiro de 2016 para refinamento de alguns dados de pesquisa. Neste momento, eu havia transcrito algumas entrevistas e juntamente com a orientadora Teresa Medina, sentíamos a necessidade de melhor esclarecer alguns pontos dos diversos depoimentos recebidos, observações registradas nas notas de campo, bem como alguns questionamentos surgidos durante as orientações via Skype.

$\mathrm{Na}$ terceira viagem a Cabo Verde permaneci durante três semanas, período em que pude participar de maneira mais intensa da dinâmica da escola, pois ao contrário da estadia anterior, nesse momento a escola estava em período de aulas.

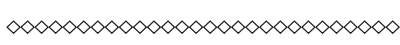

17 Sodad, palavra do crioulo cabo verdiano que significa saudade em português. 
Foram realizadas novas entrevistas com os seguintes sujeitos: Valdemar Lopes, atual diretor da escola, um professor, cinco alunos participantes de um dos projetos envolvendo o M_EIA e uma comunidade local, um membro desta mesma comunidade. A centralidade da figura do diretor na tomada de decisões na escola foi um fator importante pela opção por entrevistá-lo.

Nesta nova imersão no campo, percebi que, em muitos casos, as pessoas sentiam-se mais a vontade para falar a respeito de suas percepções sobre a escola por meio de conversas informais. Assim, tive vários encontros com o diretor, professores e alunos do M_EIA para estas conversas.

Também fui a uma comunidade onde o M_EIA estava realizando projetos de desenvolvimento local organizados por professores e alunos, para conversar com algumas pessoas que dela fazem parte. Logo ao chegar a casa, procurava relatar essas conversas com detalhes em um diário de campo, bem como as minhas impressões.

De volta ao Brasil, na segunda semana de fevereiro de 2016, iniciei em um novo trabalho como professora de arte em uma escola particular de Educação Básica. Assim, a árdua tarefa de transcrição das entrevistas, sua organização em grelhas conforme sujeito e temática tratada, a elaboração de grelhas para a organização das notas de campo, a leitura de autores cuja discussão se aproxime das temáticas recorrentes nas entrevistas, a posterior construção das categorias de análise, novas leituras e, por fim, a escrita da tese, em fase de conclusão, tiveram de ser conjugadas com o meu novo trabalho como professora, com a grande quantidade de aulas e de alunos, bem como com as longas distâncias a serem percorridas para se chegar à escola onde leciono.

Após a transcrição das entrevistas e da leitura exaustiva de cada uma delas foram detectados, com maior recorrência, os seguintes blocos temáticos:

1- Criação do M_EIA, trajetória vinculada ao Atelier Mar e aos desafios da sociedade cabo-verdiana; Papel social do M_EIA; Concepções de arte que permeiam a escola; Tensão entre por um lado, escola da arte de ensino superior, regulamentada pelo ministério da educação e, por outro lado, escola que se constitui como um projeto aberto.

2- Pesquisa Aplicada como princípio educativo na escola; Concepções de Pesquisa Aplicada; Investigação aplicada como instrumento de trabalho nas comunidades - como a M_EIA tem se apropriado desta metodologia para a construção de projetos e planos de ação; Como a pesquisa aplicada é trabalhada na formação dos alunos; Dificuldades no desenvolvimento da pesquisa aplicada.

3- Perfil dos Professores; Percepção dos professores sobre os alunos.

4- Participação dos alunos nos projetos; Percepção dos alunos sobre os projetos 
e/ou sobre a escola; Relação dos alunos com as comunidades.

5- Participação dos alunos nos projetos; Percepção dos alunos sobre os projetos e/ou sobre a escola; Relação dos alunos com as comunidades.

6- Relação entre as comunidades locais e o M_EIA; Avaliação das comunidades sobre as intervenções do M_EIA nos contextos locais.

7- Fortalecimento das potencialidades locais; Importância do conhecimento da realidade local para a realização dos projetos.

As grelhas das entrevistas foram organizadas com base nesses blocos temáticos. Estes últimos, associado à bibliografia estudada, deram origem às categorias de análise. São elas: concepções de arte e de educação artística presentes na escola; investigação participativa e investigação aplicada; articulações entre arte, educação, comunidade(s) e desenvolvimento local.

As categorias de análise, por sua vez, constituíram-se no fio condutor para a análise dos dados coletados. Neste momento realizou-se uma nova leitura acurada dos dados coletados (notas de campo, entrevistas e fontes documentais) cruzada a bibliografia anteriormente selecionada, bem como a incorporação de outros teóricos que dialogassem com os novos olhares desenvolvidos sobre o tema de estudos nesta última etapa da investigação.

Atualmente, o último capítulo da tese, o de análise de dados, está em fase de redação. As reflexões desenvolvidas a partir dos dados coletados serão publicadas, portanto em momento posterior. Contudo, lembrando Bourdieu, Chamboredon e Passeron (2007), no livro "Ofício de Sociólogo", considerou-se relevante, no presente ensaio, descrever o percurso delineado para a condução de uma investigação, nesse caso, com a peculiaridade de situar-se entre três países pertencentes a continentes diferentes, para que outros pesquisadores possam verificar quais foram as dificuldades e impasses vivenciados nesse percurso, quais foram as estratégias desenvolvidas, bem como quais foram as soluções encontradas.

\section{Considerações Finais}

Ao findar a escrita reflexiva sobre o percurso metodológico para a realização da investigação, tenho a consciência do quanto ela foge as convenções acadêmicas. Porém, não seria possível descrever os caminhos trilhados para a realização da pesquisa descolados dos desafios que os marcaram. Isto porque sentir na pele as contradições sociais, e simultaneamente realizar um doutorado, processo que exige a reflexão constante a respeito dessas mesmas contradições, é extremamente estimulante. Meu olhar sobre as 
coisas já não pode ser o mesmo... Vivo um período de criatividade na escrita, na formulação de ideias, bem como na construção de respostas e/ou alternativas para os desafios profissionais e cotidianos. Se por um lado, a empreitada para a realização da pesquisa revelou-se árdua, não tenho dúvida, de que por outro lado, os aprendizados têm sido ainda maiores.

Um desses aprendizados tem sido a descoberta da precariedade, geralmente associada em um mundo tecnológico, a aspectos negativos, como algo que carrega em si elementos de grande positividade. A própria disciplina de Arte, ao ocupar posição geralmente marginal nas escolas de educação básica em alguns países como Cabo Verde e Brasil, pode constituir-se como um espaço privilegiado para o desenvolvimento de práticas subversivas, tanto no que se refere às concepções excludentes e reducionistas sobre arte, quanto com relação às próprias concepções de educação e da dinâmica escolar, muitas vezes, marcadas por traços de excessiva rigidez. Em um plano mais amplo, pode-se afirmar que por mais que ciência e tecnologia almejem um controle da natureza e da própria vida, a arte pode ajudar-nos a refletir sobre o seu caráter precário, dada a incompletude dos seres. Compreender e aceitar isso não é somente algo extremamente belo, mas também necessário diante dos grandes impasses que o paradigma do desenvolvimento, baseado na produção e consumo desenfreados, colocam para relação dos seres humanos com o planeta.

\section{Referências bibliográficas}

ALVES, Rubem. Livro sem fim. Lisboa: ASA, 2004.

ANDRÉ, Marli. O que é um estudo de caso em Educação. Revista da FAEEBA Educação e Contemporaneidade, Salvador, v. 22, n. 40, p. 95-103, jul./dez. 2013.

ATKINSON, Dennis. Pedagogy against the State. JADE. Vol. 27, No. 3, p. 226- 240, 2008.

BOURDIEU, Pierre; CHAMBOREDON; PASSERON, Jean Claude. A Construção do Objeto. In: Ofício de Sociólogo. Metodologia da Pesquisa na Sociologia. 6 ed. Petrópolis: Vozes, 2007, p.45-72.

CLARIDADE - revista de arte e letras. Mindelo, Ilha de São Vicente: Grupo Claridade, 1936-1937.

LOPES, Baltasar. Chiquinho. Editora Ática S.A. São Paulo. 1986.

LOPES, Manuel. Os Flagelados do vento leste. 3.ed. Lisboa: Vega, 1991.

MARQUES, Mário Osório. Escrever é preciso: o princípio da pesquisa. 5. ed. Unijuí: Ijuí, 2006. 
MOUFFE, Chantal. Estratégias de política radical e resistência estética. Esquerda. net, 2014. Disponível em: http://www.esquerda.net/artigo/estrategias-de-politica-radical-e-resistencia-estetica/33990. Data de acesso: 25/03/2016.

MOUFFE, Chantal. Prácticas artísticas y democracia agonística. Barcelona, MACBA, 2007.

PAIGC. História da Guiné e Ilhas de Cabo Verde. Porto: Afrontamento, 1974.

PEREIRA, Daniel. Das relações históricas Cabo Verde/ Brasil. Brasília: Fundação Alexandre de Gusmão, 2011.

PONTO \& VÍRGULA. Edição Fac-similada. Coimbra. 2006

RANCIẼRE, Jacques. A Partilha do Sensível. São Paulo: Editora 34, 2009.

SANTOS, Boaventura de Sousa. Um discurso sobre as ciências. 16. ed. Porto: B. Sousa Santos e Edições Afrontamento, 2010.

TOMÁS, António. O fazedor de utopias: uma biografia de Amílcar Cabral. Lisboa: Tinta de China, 2007. 